\title{
Dietary Gum Arabic Supplementation Alter Plasma and Tissue Antioxidant and Free Radical Scavenging Activities in Sprague Dawley Male Rats
}

\author{
Amira Kassem (Corresponding author) \\ Genatic resource center, Sana'a University, P.O. Box 19509, Sana'a, Republic of Yemen \\ E-mail: amirabarialika@gmail.com \\ Aminah Abdullah \\ School of Chemical Sciences and Food Technology, Faculty of Science and Technology \\ Universiti Kebangsaan,Malaysia, 43600 Bangi Selangor, Malaysia
}

Received: December 23, 2014 Accepted: January 9, 2015

doi:10.5296/jbls.v6i1.6818ＵRL: http://dx.doi.org/10.5296/jbls.v6i1.6818

\begin{abstract}
The aim of this study was to determine the antioxidant activities of dietary Gum Arabic supplemented in male rat model. In this study, the Sprague Dawley rats were separated into two groups as follows: the normal control group (NC) and Gum Arabic group (GA). At the end of eight weeks of treatment, the Ferric Reducing Antioxidant Power (FRAP) , 1, 1Diphenyl-2-picryl-hydrazyl (DPPH) levels, and the total phenol content of the GA extracts, plasma and liver tissue were evaluated. The results showed an increased of plasma and liver antioxidant activates in the GA groups as compared to the NC group. Administration of dietary GA reduced the FRAP and TPC concentration in the plasma and in the liver the GA group. Based on these results, it can be concluded that GA supplemented is the natural antioxidants, especially phenolic compounds, which may act both by reducing the content of toxic compounds in foods and by supplying the human body with exogenous antioxidant.
\end{abstract}

Keywords: Gum Arabic, Extraction Solvent, DPPH radical scavenging activity, Phenolic content, Plasma antioxidant capability, Male rat.

\section{Introduction}

Gum arabic is also known as gum acacia. The source of gum arabic is the Acacia tree. The acacia grows in a region stretching from Senegal to Sudan in Africa. The Acacia Senegal Gum is a medium-sized tree with thorns growing on the African savannah grassland (James and Webb, 1985) .Gum Arabic is widely used in the pharmaceutical and food industries as an 
emulsifier and stabilizer. Acacia is comprised of saccharides and glycoproteins and is adapted to be consumed by humans (Verbeken et al., 2003).

Natural antioxidants of plants origin are known to exhibit a wide range of biological effects, including antioxidant, antibacterial, antiviral, anti-inflammatory, anti-allergic, antithrombotic and vasodilatory activity (Liyana et al.,2006) and (Zhang et al., 2011) .

It has been recorded that free radicals are involved in causing many diseases (Ames et al.,1993).Free radicals are known to be the major cause of various chronic and degenerative diseases, including aging, coronary heart disease, inflammation, stroke, diabetes mellitus and cancer (Cheng et al.,2003) and (Slater., 1984).Reactive oxygen species (ROS) include free radicals such as $\mathrm{dO}_{2}$ (superoxide anion), $\mathrm{dOH}$ (hydroxyl radical), $\mathrm{H}_{2} \mathrm{O}_{2}$ (hydrogen peroxide) and $1 \mathrm{O}_{2}$ (singlet oxygen) can cause cellular injuries and initiate peroxidation of polyunsaturated fatty acids in biological membranes (Compori., 1985) and(Halliwell., 1997). The tissue injury caused by ROS may include DNA damage (Halliwell and Gutteridge., 1984) and (Bartold., 1984), protein damage (Varani., 1985), and oxidation of important enzymes (Gamal et al.,2003) in the human body. These events could consequently lead to the occurrence of various free radical related diseases. Recently, natural foods and food derived antioxidants such as vitamins and phenolic phytochemicals have received growing attention, because they are known to function as chemopreventive agents against oxidative damage.

In folk medicine, GA has been reported to be used internally for the treatment of inflammation of the intestinal mucosa, and externally to cover the inflamed surfaces (Rehman et al., 2001). Although GA is widely used as a vehicle for drugs in physiological experiments and experimental pharmacology, and is assumed to be a substance " inert ', recent reports have claimed that GA has anti-oxidant properties, and nephroprotectant other effects (Varani et al., 1985) (Bartold et al., 1984) and (Ali et al., 2008). Clinically, it has been tried in patients with chronic renal failure, and was said it helps reduce concentrations of urea and plasma creatinine and reduces the need dialysis 3-2 times per week (Suliman et al., 2003).

Thus, the objective of this research was to evaluate the antioxidant activities of gum arabic completed in relation to their total phenolic content and trapping of free radicals in the plasma and liver of male rats.

\section{Materials and Methods}

\subsection{Chemicals}

Folin-Ciocalteu phenol reagent, ferric chloride $(\mathrm{FeCl} 3 \cdot 6 \mathrm{H} 2 \mathrm{O})$, and $\mathrm{HCl}$ were obtained from Merck (Darmstadt, Germany) and 2,2-diphenyl-1-picrylhydrazyl (DPPH), 2,4,6-tris(2pyridyl)-s-triazine (TPTZ), gallic acid and Trolox, andsodium acetate trihydrate were purchased from Sigma (USA). Sodium carbonate was purchased from RDH (Germany) while glacial acetic acid was from Mallinckrodt Baker (USA). All chemicals and reagents used in the study were of analytical grade.

\subsection{Animals and Experimental Design}

Fourteen (14) Sprague Dawley male rats each weighing between 150-200g were used in this 
experiment. After 2 weeks of adaptation, the rats were randomly divided into two treatment groups consisting seven rats in each group. They were obtained from the animal house of the Faculty of Science and Technology, Universiti Kebangsaan Malaysia. The animals were acclimatized to laboratory condition for a week before commencement of the experiment. Rats were fed ad libitum with commercial rat's food containing $10 \%$ GA. The diets were prepared daily to minimize rancidity and oxidative damage, the rats were fed once daily and the left over feeds were collected before new feeding. After two months of feeding trial, the animals were fasted overnight and the day after were killed and the liver from each animal was collected and dissected and a $20 \%$ homogenate was prepared in ice cold phosphate buffer, $\mathrm{pH} 7.4$ and centrifuged at 3,000 rpm for $15 \mathrm{~min}$ in a refrigerated centrifuge and than the supernatants were collected .It was stored at $-8^{\circ} \mathrm{C}$ until analyzed. The different types of solvent used were absolute methanol, ethanol, acetone, water and their aqueous solutions at 50\%, 70\%, and 100\% concentrations for GA extraction of antioxidant. All tests were performed at room temperature

\subsection{Determination of the Total Phenolic Contents (TPC)}

The determination of antioxidant activity through TPC was carried out according to the method of Musa et al. (2011). .The total phenolic content is determined using the Folin-Ciocalteu reagent. The phenolic compounds are oxidized to phenolates by the reagent at alkaline $\mathrm{pH}$ in a saturated solution of sodium carbonate resulting in a blue molybdenum-tungstate complex. About $0.5 \mathrm{~mL}$ of Folin-Ciocalteau $(10 \%, \mathrm{w} / \mathrm{v}$, ) is added to $0.1 \mathrm{~mL}$ sample, followed by the addition of $1 \mathrm{~mL}$ of aqueous $\mathrm{Na}_{2} \mathrm{CO}_{3}(7.5 \%$, w/v). The mixture was allowed to stand in the dark for 2 hours. The absorbance of the blue colour solution is read at $765 \mathrm{~nm}$ on a UV visible spectrophotometer ( EPOCH) against blank (distilled water). Total phenolic concentration (mg $\mathrm{mL}-1$ ) of the sample was extrapolated from a standard curve, constructed using Gallic acid as a standard.

\subsection{Free Radical Scavenging Activity}

The ability of aceton, ethanol methanolic and water extracts of GA to scavenge 1, 1-diphenyl-2-picryl-hydrazyl (DPPH) free radicals was estimated as previously described by Jain et al. (2008). The 2, 2-diphenyl-l-picrylhydrazyl assay (DPPH) is dissolved in 100\% ethanol to $200 \mu \mathrm{M}$ and sonicated for $5 \mathrm{~min}$ to obtain the stable free radical DPPH. Each GA extract $(100 \mu \mathrm{l})$ were to react with $3000 \mu \mathrm{l}$ of the DPPH solution for $24 \mathrm{~h}$ in the dark condation. The standard curve was linear between 25 and $800 \mu \mathrm{M}$ methanol. The fruit extract is tested in triplicate at different extraction solvents, such that a $50 \%$ fall in absorbance of the DPPH. The absorbance was measured by a spectrophotometer at $517 \mathrm{~nm}$ at $30 \mathrm{~min}$ intervals against a blank (pure ethanol). The percentage of radical scavenging activity was calculated using the following formula:

Radical scavenging $(\%)=[(\mathrm{A} 0-\mathrm{A} 1 / \mathrm{A} 0) \times 100]$

Where A0 is the absorbance of the control and A1 is the absorbance of the sample extracts .

\subsection{Determination of Ferric Reducing Antioxidant Power (FRAP)}

The antioxidant capacity of each sample was estimated according to adapted procedure from 
(Nabila et al., 2008). The FRAP reagent was prepared as follows : $300 \mathrm{~m} \mu$ acetate buffer, PH 3.6 ( 3.1 gm sodium acetate trihydrate, plus $16 \mathrm{ml}$ glacial acetic acid made up to 1 liter distilled water); $10 \mathrm{~m} \mu \mathrm{TPTZ}$ (2,4,6-tri (22-pyridyI)-s-triazine),in $40 \mathrm{ml} \mathrm{m \mu} \mathrm{HCL}$; and $20 \mathrm{~m} \mu$ Fecl3 $6 \mathrm{H} 2 \mathrm{O}$ in ratio $10: 1: 1$ to give the working reagent. FRAP reagent $(3950 \mu \mathrm{L})$ was prepared and warmed at $37{ }^{0} \mathrm{C}$, was mixed with $50 \mu \mathrm{L}$ test sample reaction was monitored up to $30 \mathrm{~min}$ Fruit extracts $(100 \mu \mathrm{L})$ were allowed to react with $1000 \mu \mathrm{L}$ of the FRAP solution for $30 \mathrm{~min}$ in the dark condition . The mixture was transferred to micro plate plastic and its absorbance recorded at $595 \mathrm{~nm}$ on the spectrophotometer $(\mathrm{EPOCH})$ Absorbance of a blank containing $50 \mu \mathrm{L}$ of methanol with FRAP regent was recorded .Change in absorbance of each sample was computed. Furthermore, a known antioxidant, gallic acid, was used as stander to express FRAP value of the extracts. Known concentration of gallic acid, were used to prepare a standard curve with linear regression, which was used as reference for comparing the extracts. The result was expressed as milligrams of gallic acid equivalents per $100 \mathrm{~g}$ of fresh sample (mg TE/g of FW)

\subsection{Statistical Analysis}

The results were expressed as mean \pm standard error $(n=7)$. The data were analyzed statistically by one way ANOVA and different group means were compared by Duncan's multiple range test (DMRT); $p<0.05$ was considered significant in all cases.

\section{Result}

The percentage of antioxidant activities calculated after the addition of $100 \mu$ from GA to the reaction mixture incubated at $37^{\circ} \mathrm{C}$ for $2 \mathrm{hr}$ was measured by the thiobarbituric acid reagent substances (TBARS) method (Table 1-2). This study shows that GA either exhibited increased antioxidant activity or decreased prooxidant activity.

The results showed (Table 1) that TPC, DPPH, and FRAP values were sensitive to extraction solvents whereby in pure solvents, acetone extract of GA the highest extraction efficiency followed by ethanol, methanol and water, respectively. Aqueous organic solvents were found to give the highest values. Both, 50\% acetone and ethanol were the best solvents for obtaining extracts with higher TPC activities in GA. However, with 50\% Methanol the DPPH values were significantly $(\mathrm{P}<0.05)$ lower than both $70 \%$ and $100 \%$ acetone and ethanol, and DPPH value where the three solvents showed significant differences $(\mathrm{P}<0.05)$.

Table 1. Effect of different extraction solvents on the antioxidants activities from GA determined by DPPH radical-scavenging activity, and ferric reducing antioxidant power (FRAP) and total phenolic contents

\begin{tabular}{|l|l|l|l|l|}
\hline & & DPPH & FRAP & TPC \\
\hline Acetone & $50 \%$ & $3.00 \pm 0.17^{\mathrm{a}}$ & $0.17 \pm 0.03^{\mathrm{e}}$ & $0.94 \pm 0.01^{\mathrm{a}}$ \\
\cline { 2 - 5 } & $70 \%$ & $1.96 \pm 0.03^{\mathrm{c}}$ & $0.24 \pm 0.01^{\mathrm{d}}$ & $0.53 \pm 0.01^{\mathrm{e}}$ \\
\cline { 2 - 5 } & $100 \%$ & $0.31 \pm 0.01^{\mathrm{f}}$ & $0.74 \pm 0.01^{\mathrm{a}}$ & $0.12 \pm 0.01^{\mathrm{g}}$ \\
\hline \multirow{3}{*}{ Ethanol } & $50 \%$ & $2.39 \pm 0.06^{\mathrm{b}}$ & $0.62 \pm 0.23^{\mathrm{ab}}$ & $0.89 \pm 0.01^{\mathrm{b}}$ \\
\cline { 2 - 5 } & $70 \%$ & $1.66 \pm 0.08^{\text {ed }}$ & $0.29 \pm 0.01^{\text {ed }}$ & $0.58 \pm 0.02^{\mathrm{d}}$ \\
\cline { 2 - 5 } & $100 \%$ & $0.48 \pm 0.01^{\mathrm{f}}$ & $0.75 \pm 0.01^{\mathrm{a}}$ & $0.13 \pm 0.01^{\mathrm{g}}$ \\
\hline Methanol & $50 \%$ & $1.70 \pm 0.06^{\mathrm{d}}$ & $0.52 \pm 0.10^{\mathrm{abc}}$ & $0.84 \pm 0.01^{\mathrm{c}}$ \\
\cline { 2 - 5 } & $70 \%$ & $0.48 \pm 0.01^{\mathrm{f}}$ & $0.69 \pm 0.02^{\mathrm{a}}$ & $0.16 \pm 0.01^{\mathrm{f}}$ \\
\cline { 2 - 5 } & $100 \%$ & $1.95 \pm 0.06^{\mathrm{c}}$ & $0.40 \pm 0.02^{\mathrm{bcd}}$ & $0.57 \pm 0.02^{\mathrm{d}}$ \\
\hline Water & & $1.49 \pm 0.03^{\mathrm{e}}$ & $0.77 \pm 0.03^{\mathrm{a}}$ & $0.90 \pm 0.01^{\mathrm{b}}$ \\
\hline
\end{tabular}


Values in each column marked by the same letter within the column are not significantly different at $\mathrm{P}<0.05$. Results showed mean $\pm \mathrm{SE}$.

For TPC and FRAP, the highest correlation (0.995) was observed in $100 \%$ acetone, while $100 \%$ methanol showed the lowest value. The TPC and DPPH in 70\% methanol showed the highest correlation (0.984) while70\% ethanol showed the lowest value (0.217). The 50\% acetone showed the highest correlation (0.984) and $100 \%$ methanol showed the lowest value (0.417). As for FRAP and DPPH the correlation in 50\% acetone and ethanol showed the highest correlation $(0.996,0.998)$ while distill water showed the lowest value $(0.225)$.

The total antioxidant capacity of their plasma was measured by FRAP assay. Plasma antioxidant levels increased significantly after consumption of GA compared to the control group. There was significant $\mathrm{P}<0.05$ change in liver homogenate antioxidant FRAP values over the same period after ingestion of GA compared to the control group (Table 2). However, total phenolic content of plasma and liver homogenate were significantly $\mathrm{P}<0.05$ highest compared to the control group. For TPC and FRAP, the highest correlation $(0.970)$ was observed in the liver animal treated with GA and the liver control showed the highest value $(0.845)$, while control animal group showed the highest correlation (0.922) and plasma animal treated with GA showed the highest value (0.827).

Table 2. Antioxidant potentials of GA assayed by FRAP and TPC assay in Plasma and liver of experimental and normal male rat.

\begin{tabular}{|l|l|l|l|}
\hline & & GA & Control \\
\hline \multirow{2}{*}{ Plasma } & FRAP & $3.96 \pm .085^{\mathrm{a}}$ & $3.47 \pm .11^{\mathrm{b}}$ \\
\cline { 2 - 4 } & TPC & $1.55 \pm .045^{\mathrm{a}}$ & $1.53 \pm .03^{\mathrm{b}}$ \\
\hline \multirow{2}{*}{ Liver } & FRAP & $1.73 \pm .021^{\mathrm{a}}$ & $1.46 \pm .037^{\mathrm{b}}$ \\
\cline { 2 - 4 } & TPC & $1.89 \pm .033^{\mathrm{a}}$ & $1.79 \pm .010^{\mathrm{b}}$ \\
\hline
\end{tabular}

Values are expressed as mean $\pm \mathrm{SE}(\mathrm{n}=7)$. Means with different letters were significantly different at the level of $\mathrm{P}<0.05$.

\section{Discussion}

Several methods were used to determine the antioxidant activity of plants. Our study therefore has involved three different methods established to evaluate the antioxidant activity of gum arabic (GA), namely, DPPH radical-scavenging activity, scanning activity hydroxyl radicalization, ferric reducing / antioxidant power (FRAP) analysis and capacity Total antioxidant. Phenolic compounds have been identified and the total phenolic content was also determined. This study estimated the phenolic content of the extract of acetone and ethanol extract of gum arabic. Our results showed that the extract of acetone contained significantly higher levels of phenols which methanol extract and it was agreed with (Verbeken et al., 2003), which indicated that GA is a powerful source phenolic compounds, which can be a good source of antioxidants in the food system

Our current study demonstrates that the antioxidant activity could be determined by using several test systems. However, there are several methodological limitations in determining antioxidant (2008 Jain et al.) .To Measure the antioxidant capacity of GA, we suggested that 


\section{Mll Macrothink}

Journal of Biology and Life Science

ISSN 2157-6076

2015, Vol. 6, No. 1

FRAP is a suitable method. In this study, however, the high antioxidant activity of GA methanol extract may be due to the majority of the active compounds in the GA being dissolved in the methanol solvent (white solid) (Kaur and Kapoor., 2001). The DPPH assay is one of the most common and relatively quick methods used to test the radical scavenging activity of various plant extracts (Rahmat et al., 2006)

The results of this study indicated that the methanol extract was significantly lower than that of acetone. These results agree with the results of (Lillian et al., 2008) with experience on the antioxidant and antimicrobial activities of the Pistacia lentiscus and extracts from Pistacia atlantica. Statistical correlations were investigated between phenol content and total antioxidant activity determined by various tests. The total phenol content was shown to provide the best combination with FRAP assay in this study $(\mathrm{R} 2=0.995)$. This result is also consistent with (Nabila et al., 2008), who found a strong positive correlation between the content of total phenolics and FRAP assay. All of these studies were based on the assumption that GA has strong anti-oxidant, and a major mechanism for the induction of these toxicities is the generation of free radicals (Benzie and Stezo., 1999) and (Ali and Al Moundhri ., 2006).

The FRAP method was applied in this study, which appears to be highly reproducible and adapted to detect small increases in antioxidant activity. Recently, the same method FRAP was used in a study in which significant increases in plasma antioxidant capacity could be detected due to the consumption of wine (Hinson et al., 2004). The dietary supplement of the effect of GA on the antioxidant capacity was observed in the plasma and liver tissue antioxidant analysis and the results showed that the modification of the feed GA produced statistically significant changes in plasma and consumer liver tissue .The GA caused a significant increase in both plasma FRAP and TPC, increased the antioxidant capacity of plasma observed after the consumption of foods rich in flavonoids often far exceeds the increase in plasma flavonoids (Duthie and al.1988). Also significantly increased antioxidant liver tissue were consistent with (and Balz Frei Silvina. 2004) who reported gum arabic has been claimed to act as an antioxidant and protective against experimental hepatic-, renal- and toxicities heart in rats .The increase in plasma and liver total antioxidant capacity observed after the consumption of GA supply agreement with the result reported by (Ali et al., 2009) that the administration of GA at concentrations of $2.5 \%, 5.0 \%$ and $10.0 \%$ in drinking water for eight consecutive days to rats did not significantly affect either the concentrations of free radical scavengers, reduced glutathione (GSH), the ascorbic acid (AA), and superoxide dismutase (SOD), or lipid peroxidation. This finding seems to suggest that there is evidence that GA has a strong antioxidant action. These results also showed bumping GA to affect the oxidation of the liver homogenate at varying degrees, where antioxidant activity differs depending on the level of GA added to the system. Therefore, these differences could be attributed to differences in level of botanical GA and also to the presence of various antioxidant compounds such as flavonoids (Ali. 2004) phenolic acids and phenolic diterpenes (Pietta et al., 1998) that have different antioxidant (Shahidi et al., 1992) and (Vinson et al., 1997). Studies by Hodnick et al (1988) Showed that flavonoids with hydroxyl groups have been most easily oxidized. The differences in the antioxidant activities depend primarily structural differences of the degree of hydroxylation and methylation of compounds. In addition, the data reported by Gazzani et al. 
(1998) indicate that some phenolic compounds, such as antioxidants, can respond more quickly than others in the same conditions. In addition, the presence of constituents other than the phenolic compounds such as vitamins $\mathrm{C}, \mathrm{E}$ and carotenoids may influence the total antioxidant activity (Shahidi et al., 1992) and (Vinson et Hontz., 1995).

From the results presented above, it is clear the Gum Arabic studied are good sources of antioxidant compounds. Currently, the total antioxidant activity values presented in this work are of interest for a comparative in vitro evaluation of total antioxidant activity of Gum Arabic extracts. However, these values are combined with in vivo data to properly evaluate the effectiveness of the antioxidant of the gum arabic

In conclusion, the data indicates that the composition of male rat plasma and membrane antioxidant is significantly altered during feeding with GA. Rats fed with GA had higher antioxidant capacity in plasma and tissues as compared to control groups. This indicated that GA has strong anti-oxidant properties have the potential to significantly alter general tissue and plasma antioxidant capacity.

\section{Acknowledgements}

This work was supported by Universiti Kebangsaan,Malaysia research grant through project UKM-OUP-NBT-29-139/2011.Authors want to thank the Natural Prebiotic (M) Sdn.Bhd for provided gum Arabic (Mnna) for the research .

\section{References}

James L. A. Webb Jr. (1985). The Trade in Gum Arabic: Prelude to French Conquest in Senegal. Journal of African history, 26, 49-168,. http://dx.doi.org/10.1017/S0021853700036914

Verbeken. D. Dierckx .S. K. (2003) . Dewettinck Exudate gums: occurrence, production, and application. Applied Microbiology and Biotechnology, 63, 10-213. http://dx.doi.org/10.1007/s00253-003-1354-z

Liyana PCM, Shahidi .(2006). Antioxidant properties of commercial soft and hard winter wheats (Triticum aestivum L.) and their milling fractions. Journal of the Science of Food and Agriculture, 86, 477-485. http://dx.doi.org/10.1002/jsfa.2374

Zhang, L., Ravipati, A. S., Koyyalamudi, S. R., Jeong, S. C., Reddy, N., Smith, P. T., Bartlett, J.( 2001). Antioxidant and Anti-inflammatory Activities of Selected Medicinal Plants Containing Phenolic and Flavonoid Compounds Journal of the Science of Food and Agriculture, 59(23).

Ames BN, Shigenaga MK, and Hagen TM .(1993). Oxidants, antioxidants and the generative disease of aging. Proceedings of the National Academy of Sciences of the United States of America, 90, 7915-7922. http://dx.doi.org/10.1073/pnas.90.17.7915

Cheng, H. Y., Lin, T. C., Yu, K. H., Yang, C. M., \& Lin, C. C.(2001). Antioxidant and free radical scavenging activities of Terminalia chebula. Biological \& Pharmaceutical Bulletin. 26, 1331-1335. http://dx.doi.org/10.1248/bpb.26.1331 
Slater, T. F. (1984). Free-radical mechanisms in tissue injury. Biochemical Journal, 222, 1-15.

Compori, M. (1985). Lipid peroxidation and cellular damage in toxic liver injury. Laboratory Investigation, 53, 599-620.

Halliwell, B. (1997). Antioxidants and human disease: A general introduction. Nutrition Reviews, 55, 44-52 http://dx.doi.org/10.1111/j.1753-4887.1997.tb06100.x

Halliwell, B., \& Gutteridge, J. M. (1984). Lipid peroxidation, oxygen radicals, cell damage, and antioxidant therapy. Lancet , 23, 1396-1397. http://dx.doi.org/10.1016/S0140-6736(84)91886-5

Bartold, P. M., Wiebkin, O. W., \& Thonard, J. C.( 1984). The effect of oxygen-derived free radicals on gingival proteoglycans and hyaluronic acid. Journal of Periodontology, 19, 390-400. http://dx.doi.org/10.1111/j.1600-0765.1984.tb01012.x

Varani, J., Fligiel, S. E. G. ., Till, G. O., Kunkel, R. G. , Ryan, V. S., \& Ward, P. A.(1985). Pulmonary endothelial cell killing by human neutrophils: possible involvement of hydroxyl radical. Laboratory Investigation, 656-663.

Gamal el-din, A. M., Mostafa, A. M., Al-Shabanah, O. A., Al-Bekairi, A. M., Nagi, M.N.(2003). Protective effect of arabic gum against acetaminophen-induced hepatotoxicity in mice. Pharmacological Research, 48, 631-635. http://dx.doi.org/10.1016/S1043-6618(03)00226-3

Rehman, K., Wingertzahn, M.A., Harper, R.G., Wapnir, R.A.(2001). Proabsorptive action of G.A.: regulation of nitric oxide metabolism in the basolateral potassium channel of the small intestine. Journal of Pediatric Gastroenterology and Nutrition, 32, 529-533. http://dx.doi.org/10.1097/00005176-200105000-00008

Ali, A. A., K. E. Ali, A. Fadlalla \& K. E. Khalid.(2008). The effects of G.A. oral treatment on the metabolic profile of chronic renal failure patients under regular haemodialysis in Central Sudan. Natural Products Research, 22, 12-21. http://dx.doi.org/10.1080/14786410500463544

Suliman, S. M., Hamdouk, M. I., Elfaki, M. B. G.A. (2003). fiber as a supplement to low protein diet in chronic renal failure patients. In: Sudan Association of Physicians, 17th Conference, Friendship Hall, Khartoum, Sudan, 21-23 March. Superk.

Musa, K. H., Abdullah, A., Jusoh, K., \& Subramaniam,V. (2011). Antioxidant activity of pink-flesh guava (Psidium guajava L.): effect of extraction techniques and solvents. Food Analytical Methods, 4(1), 100-107. http://dx.doi.org/10.1007/s12161-010-9139-3

Jain A, Soni M, Deb L, Jain A, Rout S, Gupta V, Krishna K.(2008). Antioxidant and hepatoprotective activity of ethanolic and aqueous extracts of Momordica dioica Roxb. leaves. Journal of Ethnopharmacol, 115, 61-66. http://dx.doi.org/10.1016/j.jep.2007.09.009

Kaur, C., \& Kapoor, H. C.(2001). Antioxidants in fruits and vegetables-the millennium's health. International Journal of Food Science and Technology, 36, 703-725. http://dx.doi.org/10.1046/j.1365-2621.2001.00513.x 
Rahmat, A., S. Edrini, A.M. Akim, P. Ismail, Y.H. Yap and M.F. Abu bakar.(2006). Anticarcinogenic properties of strobilanthes crispus extracts and its compounds in vitro. International Journal of Cancer Research, 2, 47-49. http://dx.doi.org/10.3923/ijcr.2006.47.49

Lillian Barros, Telma Cruz, Paula Baptista, Letícia M. Estevinho \& Isabel Ferreira.(2008).Wild and commercial mushrooms as source of nutrients and nutraceuticals. Food and Chemical Toxicology, 46, 2742-2747. http://dx.doi.org/10.1016/j.fct.2008.04.030

Nabila, B., Fawzia, A. B., \& Tatjana, K. P. (2008). The antioxidant and antimicrobial activities of the Pistacia lentiscus and Pistacia atlantica extracts. African Journal of Pharmacy and Pharmacology, 2, 022-028.

Benzie, I. F., \& Stezo, Y. T.(1999). Total antioxidant capacity of teas by the ferric reducing reducing/antioxidant power assay. The Journal of Agricultural and Food Chemistry, 47, 633-636. http://dx.doi.org/10.1021/jf9807768

Ali, B.H., Al Moundhri, M.S.(2006). Agents ameliorating or augmenting the nephrotoxicity of cisplatin and other platinum compounds: a review of some recent research. Food and Chemical Toxicology, 44, 1173-1183. http://dx.doi.org/10.1016/j.fct.2006.01.013

Hinson, J. A., Reid, A. B., McCullough, S. S., James, L. P. (2004). Acetaminophen-induced hepatotoxicity: role of metabolic activation, reactive oxygen/nitrogen species, and mitochondrial permeability transition. Drug Metabolism Reviews, 36, 805-822. http://dx.doi.org/10.1081/DMR-200033494

Duthie GG, Pedersen MW, Gardner PT, Morrice PC, Jenkinson AMcE, McPhail DB \& Steele GM. (1988) . The effect of whisky and wine consumption on total phenol content and antioxidant capacity of plasma from healthy volunteers. European Journal of Clinical Nutrition, 52, 733-736. http://dx.doi.org/10.1038/sj.ejcn.1600635

Silvina B. Lotito \& Balz Frei.(2004). The increase in human plasma antioxidant capacity after apple consumption is due to the metabolic effect of fructose on urate, not apple-derived antioxidant flavonoids. Free Radical Biology and Medicine, 37, 251-258. http://dx.doi.org/10.1016/j.freeradbiomed.2004.04.019

Ali BH, Ziada A, Blunden G. (2009). Biological effects of gum arabic: a review of some recent research. Food and Chemical Toxicology, 47, 1-8. http://dx.doi.org/10.1016/j.fct.2008.07.001

Ali, B. H. (2004). Does G.A. have an antioxidant action in rat kidney? Renal failure, 26, 1-3.

Pietta P, Simonetti P and Mauri P.(1998). Antioxidant activity of selected medicinal plants. The Journal of Agricultural and Food Chemistry, 46, 4487-4490. http://dx.doi.org/10.1021/jf980310p

Shahidi F., Janitha P. K., \& Wanasundara P. D. (1992). Phenolic antioxidants. Critical Reviews in Food Science and Nutrition. 32, 67-105. http://dx.doi.org/10.1080/10408399209527581

J. A Vinson, Y. A Dabbagh, M. M Serry \& J Jang. (1995). Plant flavonoids, especially tea flavonols, are powerful antioxidants using in vitro oxidation model for heart disease. The 
Journal of Agricultural and Food Chemistry, 43, 2800-2802. http://dx.doi.org/10.1021/jf00059a005

Mayer A. S., Donovan J. L., Pearson D. A., Waterhouse A. L., \& Frankel E. N. (1998). Fruit hydroxycinnamic acids inhibit human low-density lipoprotein oxidation in vitro. The Journal of Agricultural and Food Chemistry, 46, 1783-1787. http://dx.doi.org/10.1021/jf9708960

Hodnick W. F., Milosavljevic E. B., Nelson J. H., \& Pardini R. S. (1988). Electrochemistry of flavonoids. Biochemical Pharmacology. 37, 2607-2611. http://dx.doi.org/10.1016/0006-2952(88)90253-5

Gazzani G., Papetti A., Daglia M., Berte F., \& Gregotti C. (1998). Protective activity of water soluble components of some common diet vegetables on rat liver microsomes and the effect of thermal treatment. The Journal of Agricultural and Food Chemistry, 46, 4123-4127. http://dx.doi.org/10.1021/jf980301g

Vinson J. A., \& Hontz B. A. (1995). Phenol antioxidant index. The Journal of Agricultural and Food Chemistry, 43, 401-403. http://dx.doi.org/10.1021/jf00050a027

\section{Copyright Disclaimer}

Copyright for this article is retained by the author(s), with first publication rights granted to the journal.

This is an open-access article distributed under the terms and conditions of the Creative Commons Attribution license (http://creativecommons.org/licenses/by/3.0/). 